\title{
Caveats in Diagnosis of Helicobacter Pylori Infection can be Avoided by a Panel of Serum Biomarkers (GastroPanel $\left.{ }^{\circledR}\right)$
}

\author{
Kari Syrjänen ${ }^{1,2^{*}}$ \\ ${ }^{1}$ Department of Clinical Research, Biohit Oyj, Helsinki, Finland \\ ${ }^{2}$ Molecular Oncology Research Center, Barretos Cancer Hospital, Barretos, SP, Brazil
}

*Corresponding author: Kari Syrjänen, Department of Clinical Research, Biohit Oyj, Laippatie 1, FIN-00880 Helsinki, Finland, Tel: 358-40-5566810; E-mail: kari.syrjanen@biohit.fi

Received date: December 13, 2016; Accepted date: December 16, 2016; Published date: December 19, 2016

Copyright: $@ 2016$ Syrjänen K. This is an open-access article distributed under the terms of the Creative Commons Attribution License, which permits unrestricted use, distribution, and reproduction in any medium, provided the original author and source are credited.

Keywords: Helicobacter pylori; Serum biomarkers; Diagnosis

\section{Dear Editor}

The understanding on the important role played by Helicobacter pylori (HP) infection in pathogenesis of gastric cancer (GC) and peptic ulcer disease has increased progressively since the discovery of the bacteria in 1984 by Marshall and Warren [1]. According to the current concepts, GC develops from HP-infection through precursor lesions of progressively increasing severity: mild, moderate and severe atrophic gastritis (AG), accompanied by intestinal metaplasia (IM) and dysplasia. This sequence of events is generally known as the "Correa cascade", and estimated to be involved in around $50 \%$ of GC cases, particularly the intestinal type of GC [2-4].

In parallel with the increased understanding of the pathogenetic mechanisms, also the management of HP- infection has undergone substantial development during the past decade. In this context, the term management also covers the complex topics related to the diagnosis of HP-infections. Much of this favourable development can be attributed to the European Helicobacter Study Group that took its first initiative in 1996 in Maastricht to gather dedicated experts to review all relevant clinical data to draft the recommendations for the clinical management of HP-infection [5]. Since then, these Maastricht conferences have been repeated every $4-5$ years, and each of these has yielded a Consensus Report, the latest being published in 2012 [6]. In parallel, attempts to standardize HP-diagnosis and treatment in individual countries have led to several national guidelines [7]. In these reports [6-10], considerable attention has been paid to different diagnostic methods used for HP detection, including comprehensive review of the advantages and limitations of each technique in different settings.

Far too often in daily practice, however, only the merits of the commonly used HP tests are being emphasized while there is a common tendency to neglect the limitations of their use, despite the fact that these are clearly identified in all European Consensus Reports since $1996[5,6,9,10]$. This applies to both of the most widely used HP tests; the 13C-Urea Breath Test (UBT) and Stool Antigen test (SAT), although Professor Marshall who discovered HP [1] made an early warning of their potential limitations already 20 years ago [11].

The voluminous literature accumulated on different HP tests during the past two decades was critically assessed recently, with special emphasis on the limitations of these tests in special clinical settings [12]. Based on these data, there is little doubt that several clinical conditions seriously hamper the diagnostic value of both the UBT and
SAT: either false-negative (up to $40 \%$ ) or false-positive results are not uncommon [12-16].

Basically, the false-negative results in UBT and SAT are due to decreased bacterial loads in the stomach mucosa, in which case the bacterial load falls below the test threshold $[6,8]$. Indeed, such a significant decrease of the HP load in the stomach arises from the following conditions: i) use of antimicrobial agents, ii) use of antisecretory drugs (PPI), and iii) in bleeding ulcers. Importantly, bacterial load may be permanently low also in premalignant and malignant lesions, including i) AG, ii) IM or iii) MALT (mucosal associated lymphatic tissue) lymphoma $[17,18]$. The specific impact of all these conditions on false-negative UBT/SAT results are discussed in detail elsewhere [12].

Since the late 1990's, it has been well established that UBT also gives false-positive results in cases where urease-producing bacterial species [19-22] or yeast-like organisms [20] are colonizing an acid-free stomach resulted from i) AG or ii) a long-term use of proton pump inhibitors (PPI) [19-22]. In fact, this possibility of false-positive UBT results was well known already in the late 1990's, when Prof. Marshall describes such findings in an HP textbook [11].

In addition to these false-negative and false-positive results of UBT and SAT testing, it is to be emphasized that neither of these two tests is capable of diagnosing AG (caused by HP-infection or autoimmune disease), thus missing the patients at high risk for the important clinical sequels of AG: i) GC, ii) esophageal cancer, iii) vitamin-B12 deficiency (due to malabsorption), and iv) malabsorption of calcium, iron, magnesium and certain medicines [23-25].

Outside the HP community, it is less well known that there is one test on the market that $i$ ) is free from the above listed shortcoming of the UBT and SAT, and in addition, ii) is capable of diagnosing both HP and AG, with all their potential sequels. This test is GastroPanel ${ }^{\circ}$, developed by a Finnish biotechnology company Biohit Oyj (Helsinki) as the first non-invasive diagnostic test for dyspeptic patients and for screening of the GC risks (HP, AG) [25].

Detailed specifications of the GastroPanel ${ }^{\circ}$ test are found elsewhere [26]. This ELISA-based biomarker panel includes 3 markers of gastric mucosal atrophy: pepsinogen I and II (PGI, PGII) for the corpus, and gastrin-17 (G-17) for the antrum, combined with HP IgG antibody assay [26-28]. The results of GastroPanel ${ }^{\circ}$ are interpreted by a special software (GastroSoft ${ }^{\circledR}$ ), classifying the marker profile into one of 8 diagnostic categories. During the past decade, GastroPanel ${ }^{\oplus}$ has been tested in both diagnostic and screening settings. In a recent metaanalysis covering all the published literature [29], GastroPanel ${ }^{\bullet}$ proved 
to be a highly accurate test for diagnosis AG both in the antrum and corpus.

GastroPanel ${ }^{\circledR}$ test has been on the market for roughly 10 years by now. This test is the first non-invasive diagnostic tool based on physiology of 3 stomach-specific biomarkers both in health and disease. The test also includes testing for HP-infection, the key etiological factor in pathogenesis of peptic ulcer disease and GC [26]. The test will be soon available in the quick test version as well, particularly suitable for POC (point-of-care) testing in doctors' offices lacking the facilities for blood sample centrifugation. With the refined diagnostic algorithm of the GastroSoft ${ }^{\oplus}$, the results are classified into 8 diagnostic categories [28], of which 5 represent functional disturbances (in acid output) and 3 indicate AG (and its topographic location).

In GastroPanel ${ }^{\circ}$ test, the HP antibody measurement is complemented by the other 3 biomarkers (PGI, PGII, G-17) which are sensitive indicators of mucosal inflammation. This is important because like all bacteria, also HP will induce acute inflammation in the gastric mucosa [25]. Accordingly, in GastroPanel ${ }^{\bullet}$ test, three different marker profiles can be encountered in association with HP-infection [26]. First, in an active HP-infection, HP-antibody titers are raised, which can be the only abnormal finding in GastroPanel ${ }^{\circ}$, with all other markers falling within a normal range. Not infrequently, however, an active on-going HP-infection causes a severe inflammatory reaction which, due to increased cell permeability, can lead to increased leakage of PGI, PGII and even G-17 from the cells and result in elevated serum levels of any or all of these three biomarkers $[6,26,28]$. Second, a successful HP-eradication by active treatment should result in normalized values of all three markers, however, with a delay of some weeks to months. HP-antibody titers can remain elevated for a longer period of time which is unpredictable (usually months) and should be taken into account while interpreting the GastroPanel ${ }^{\circledR}$ results after HP-eradication $[6,26]$. Third, in cases where HP-eradication attempt fails, HP-antibody titers remain elevated (usually slightly), PGI and PGI/PGII ratio usually fall within the normal range, whereas PGII and/or G-17b may remain slightly elevated due to ongoing inflammatory process $[6,26,28]$. The result can be confirmed after 5-6 months, followed by a new treatment attempt if indicated.

With all these sophisticated diagnostic properties [26], this panel of 4 biomarkers makes GastroPanel ${ }^{\circledR}$ test the most comprehensive HP test, devoid of the known shortcomings of the conventional HP tests [11-22]. In 2012, the International Helicobacter pylori Study Group stated in their Maastricht IV Consensus Conference, that the blood biomarker tests are a reliable means to identify and screen for gastric diseases and their risk status [6]. In the same year, 16 experts from 12 countries in the HSI (Healthy Stomach Initiative, http: Iwww.hsinitiative.org) published a set of recommendations implicating that the biomarker tests are suitable for both screening of asymptomatic patients and for diagnosis of dyspeptic patients [26].

Taken together, because firmly documented [11-22] and repeatedly emphasized in several international consensus reports [5-10], it is mandatory that the potential limitations of the globally most widespread HP detection tests (UBT and SAT) are properly recognized. It is equally important that both the false-negative and false-positive results are acknowledged as established shortcomings of these two HP tests. Furthermore, it should be emphasized that neither UBT nor SAT are capable of diagnosing AG with all its potentially severe clinical sequels, including the risk of GC. Given that Helicobacter pylori is the single most important risk factor of GC, it is time to move a step forward also in the diagnosis of HP-infections, and start using the test that is i) free from the shortcoming of the conventional HP tests, and ii) provides an added value by detecting (with high precision) [29] also the other key risk factor of GC, i.e. atrophic gastritis.

\section{References}

1. Marshall BJ, Warren JR (1984) Unidentified curved bacilli in the stomach of patients with gastritis and peptic ulceration. Lancet 1: 1311-1315.

2. Correa P, Haenszel W, Cuello C (1990) Gastric precancerous process in a high risk population: cohort follow-up. Cancer Res 50: 4737-4740.

3. Sipponen P, Kekki M, Haapakoski J, Ihamäki T, Siurala M (1985) Gastric cancer risk in chronic atrophic gastritis: statistical calculations of crosssectional data. Int J Cancer 35: 173-177.

4. Ohata H, Kitauchi S, Yoshimura N (2004) Progression of chronic atrophic gastritis associated with Helicobacter pylori infection increases risk of gastric cancer. Int J Cancer 109: 138-143.

5. Malfertheiner P, Megraud F, O'Morain C (1997) Current European concepts in the management of helicobacter pylori infectionethe Maastricht consensus report. The European helicobacter pylori study group (EHPSG). Eur J Gastroenterol Hepatol 9: 1-2.

6. Malfertheiner P, Megraud F, O'Morain CA, Atherton J, Axon AT, et al. (2012) European Helicobacter Study Group. Management of Helicobacter pylori infection--the Maastricht IV/ Florence Consensus Report. Gut 61: 646-664.

7. Fritz N, Birkner B, Schusdziarra V (2000) Are guidelines followed in Heli-cobacter pylori diagnosis and therapy? An inquiry among gastroenterologists, referring physicians and patients in Munich. Zeitschrift fur Gastroenterologie 38: 349-355.

8. Zagari RM, Romano M, Ojetti V, Stockbrugger R, Gullini S, et al. (2015) Guidelines for the management of Helicobacter pylori infection in Italy: The III Working Group Consensus Report 2015. Dig Liver Dis 47: 903-912.

9. Malfertheiner P, Megraud F, O'Morain C (2002) Current concepts in the management of Helicobacter pylori infectionethe Maastricht 2-2000 Consensus Report. Aliment Pharmacol Ther 16: 167-180.

10. Malfertheiner P, Megraud F, O'Morain C (2007) Current concepts in the management of Helicobacter pylori infection: the Maastricht III Consensus Report. Gut 56: 772-781.

11. Marshall B (1996) The 14C urea breath test. In: Lee A, Megraud F. (eds). Helicobacter pylori: Techniques for clinical diagnosis and basic research. 2nd Ed. London: WB Saunders Company 1996: 83-93.

12. http://www.biohithealthcare.com/limitations-of-helicobacter-pyloridiagnostics.

13. Ferwana M, Abdulmajeed I, Alhajiahmed A (2015) Accuracy of urea breath testin Helicobacter pylori infection: meta-analysis. World J Gastroenterol 2: 1305-1314.

14. Levine A, Shevah O, Shabat-Sehayek V (2004) Masking of 13C-urea breath test by proton pump inhibitors is dependent on type of medication: comparison between omeprazole, pantoprazole, lansoprazole and esomeprazole. Aliment Pharmacol Therapeut 20: 117-122.

15. Asfeldt AM, Lochen ML, Straume B (2004) Accuracy of monoclonal antibody-based stool antigen test in the diagnosis of Helicobacter pylori infection. Scand J Gastroenterol 39: 1073-1077.

16. Vaira D, Gatta L, Ricci C (2001) Helicobacter pylori: diseases, tests and treatment. Digest Liver Dis 33: 788-794.

17. Lehours P, Ruskone-Fourmestraux A, Lavergne A (2003) Which test to use to detect Helicobacter pylori infection in patients with low-grade gastric mucosa-associated lymphoid tissue lymphoma? Am J Gastroenterol 98: 291-295.

18. Kokkola A, Rautelin H, Puolakkainen P (1998) Positive result by serology indicates active Helicobacter pylori infection in patients with atrophic gastritis. J Clin Microbiol 36: 1808-1810.

19. Lahner E, Vaira D, Figura N, Pilozzi E, Pasquali A, et al. (2004) Role of Noninvasive Tests (13C-Urea Breath Test and Stool Antigen Test) as 
Citation: Syrjänen K (2016) Caveats in Diagnosis of Helicobacter Pylori Infection can be Avoided by a Panel of Serum Biomarkers (GastroPanel囚). J Carcinog Mutagen 7: e123. doi:10.4172/2157-2518.1000e123

Page 3 of 3

Additional Tools in Diagnosis of Helicobacter Pylori Infection in Patients with Atrophic Body Gastritis. Helicobacter 9: 436-442.

20. Gurbuz AK, Ozel AM, Narin Y, Yazgan Y, Baloglu H, et al. (2005) Is the remarkable contradiction between histology and 14C urea breath test in the detection of Helicobacter pylori due to false-negative histology or false-positive 14C urea breath test? J Int Med Res 33: 632-640.

21. Brandi G, Biavati B, Calabrese C, Granata M, Nannetti A, et al. (2006) Urease-positive bacteria other than Helicobacter pylori in human gastric juice and mucosa. Am J Gastroenterol 101: 1756-1761.

22. Osaki T, Mabe K, Hanawa T, Kamiya S (2008) Urease-positive bacteria in the stomach induce a false-positive reaction in a urea breath test for diagnosis of Helicobacter pylori infection. J Med Microbiol 57: 814-819.

23. Sipponen P, Graham D (2007) Importance of atrophic gastritis in diagnostics and prevention of gastric cancer: application of plasma biomarkers. Scand J Gastroenterol 42: 2-10.

24. Sipponen P, Laxén F, Huotari K, Härkönen M (2003) Prevalence of low vitamin B12 and high homocysteine in serum in an elderly male population: association with atrophic gastritis and Helicobacter pylori infection. Scand J Gastroenterol 38: 1209-1216.
25. Agréus L, Kuipers EJ, Kupcinskas L, Malfertheiner P, Di Mario F, et al. (2012) Rationale in diagnosis and screening of atrophic gastritis with stomach-specific plasma biomarkers. Scand J Gastroenterol 47: 136-147.

26. http://www.biohithealthcare.com/products/diagnostics-tests/products/1/ gastropanel.

27. Väänänen $H$, Vauhkonen $M$, Helske $T$, Kääriäinen I, Rasmussen $M$, et al (2003) Non-endoscopic diagnosis of atrophic gastritis with a blood test. Correlation between gastric histology and serum levels of gastrin-17 and pepsinogen I: a multi-centre study. Eur J Gastroenterol Hepatol 15: 885-891.

28. Syrjänen KJ, Sipponen P, Härkönen M, Peetsalu A, Korpela S (2015) Accuracy of GastroPanel testing in detection of atrophic gastritis. Eur J Gastroenterol Hepatol 27: 102-104.

29. Syrjänen K (2016) A Panel of serum biomarkers (GastroPanel ${ }^{\circ}$ ) in noninvasive diagnosis of atrophic gastritis. Systematic review and metaanalysis. Anticancer Res 36: 5133-5144. 